\title{
Dexmedetomidine alleviates airway hyperresponsiveness and allergic airway inflammation through the TLR4/NF-kB signaling pathway in mice
}

\author{
SHILIN XIAO*, QIANYU WANG* , HUIBIN GAO, XUMIN ZHAO, JUAN ZHI and DONG YANG \\ Department of Anesthesiology, Plastic Surgery Hospital, Chinese Academy of Medical Sciences and \\ Peking Union Medical College, Beijing 100144, P.R. China
}

Received August 16, 2021; Accepted December 20, 2021

DOI: $10.3892 / \mathrm{mmr} .2022 .12590$

\begin{abstract}
Dexmedetomidine (DEX) suppresses inflammatory responses and protects against organ injury. The aim of the present study was to investigate the effect of DEX on airway hyperresponsiveness (AHR) and allergic airway inflammation, as well as its underlying mechanism of action in a murine model of ovalbumin (OVA)-induced asthma. A total of 30 female BALB/c mice were divided into 6 groups $(n=5$ mice/group): Control, OVA, OVA + DEX (20,30 or $50 \mu \mathrm{g} / \mathrm{kg})$ and OVA + TAK-242 [a toll-like receptor 4 (TLR4) inhibitor]. The mice were intraperitoneally injected with 20,30 or $50 \mu \mathrm{g} / \mathrm{kg}$ DEX $1 \mathrm{~h}$ before OVA challenge. AHR to inhaled methacholine (Mch) was measured, and the mice were sacrificed $24 \mathrm{~h}$ after the last challenge. AHR following Mch inhalation was measured using the FlexiVent apparatus. Hematoxylin and eosin, periodic acid-Schiff and Wright-Giemsa staining was performed to evaluate inflammatory cell infiltration in the lung tissue. The levels of IL-4, IL-5 and IL-13 in the bronchoalveolar lavage fluid were analyzed using ELISA, and their mRNA expression levels in the lung tissue were examined using reverse transcription-quantitative PCR. The protein expression of TLR4, NF- $\kappa \mathrm{B}$ and phosphorylated (p) $\mathrm{NF}-\kappa \mathrm{B}$ in the lung tissue was also detected using immunohistochemistry. In the murine OVA-induced asthma model, DEX decreased AHR following Mch inhalation and reduced the infiltration of inflammatory cells. IL-4, IL-5 and IL-13 levels in the bronchoalveolar lavage fluid were significantly
\end{abstract}

Correspondence to: Professor Dong Yang, Department of Anesthesiology, Plastic Surgery Hospital, Chinese Academy of Medical Sciences and Peking Union Medical College, 33 Badachu Road, Shijingshan, Beijing 100144, P.R. China

E-mail: yangdonglin28@126.com

*Contributed equally

Key words: dexmedetomidine, allergic asthma, airway inflammation, airway hyperresponsiveness, toll-like receptor 4/nuclear factor- $\kappa \mathrm{B}$ pathway lower following DEX treatment. Furthermore, DEX treatment inhibited the expression of TLR $4, N F-\kappa B$ and $p-N F-\kappa B$ in the lung tissue and exhibited a similar effect to TAK-242 treatment. In conclusion, DEX may attenuate AHR and allergic airway inflammation by inhibiting the TLR4/NF- $\kappa$ B pathway. These results suggested that DEX may represent a potential anti-inflammatory agent for the treatment and management of patients with asthma.

\section{Introduction}

Asthma is one of the most common chronic airway inflammatory conditions in adults and children (1), affecting 5-10\% of the global population (2). It is predominantly mediated by $\mathrm{T}$ helper (Th) 2 cells and characterized by eosinophilic airway inflammation, mucus hypersecretion and airway hyperresponsiveness (AHR) (1). Asthma is an important public health issue owing to its increasing incidence, with the incidence increasing from 9.3 to $11.5 \%$ in young adults between 2008 and 2016 (3) and substantial economic burden (4). Patients with asthma undergoing surgery are at great risk of perioperative morbidity and mortality due to bronchospasms and hypoxemia (5). Although medical treatment that can relax bronchial smooth muscle (6) or inhibit leukotriene production (7) is available, the development of additional approaches to relieve these life-threatening symptoms during the perioperative period may be beneficial for patients with asthma.

Allergic airway inflammatory responses are characterized by eosinophil and Th2 cell infiltration, secretion of type- 2 cytokines and elevated immunoglobulin E levels (8). Cytokines derived from Th2 cells, including IL-4, IL-5 and IL-13, enhance airway eosinophilia, mucus production and AHR, and are involved in the pathogenesis of asthma (9). Therefore, targeting these cytokines could represent an effective therapeutic approach, as previous studies have demonstrated that reduced levels of these cytokines can relieve the typical symptoms of asthma $(10,11)$.

Various signaling pathways have been studied with respect to the pathophysiology of asthma. Among them, the toll-like receptor (TLR) family of conserved pattern-recognition receptors, has been demonstrated to serve a pivotal role in asthma $(12,13)$. TLR4, in particular, can be activated by 
bacterial lipopolysaccharide, which is the main component of the cell wall of Gram-negative bacteria (14). Activation of TLR4 can initiate inflammatory responses by targeting myeloid differentiation primary response gene 88 and NF- $\mathrm{NB}$. The TLR4/NF- $\mathrm{B}$ pathway has been demonstrated to trigger airway inflammation and AHR by promoting cytokine production (15-17).

Dexmedetomidine (DEX) is a selective $\alpha 2$ adrenoceptor that is widely used in the clinic, as it can induce sedation and analgesia, as well as reduce anxiety, without respiratory depression (18). In addition, the anti-inflammatory properties of DEX have also been examined, since they may attenuate acute multiple organ injury (19). Several studies have reported that DEX may have a protective effect on pulmonary dysfunction (20,21). However, whether DEX could alleviate AHR and allergic airway inflammation in asthma is unclear, and the potential underlying mechanism remains unknown. Therefore, the aim of the present study was to evaluate the effect of DEX on airway inflammation and AHR in allergic asthma and to examine its potential effect on the TLR4/NF- $\mathrm{B}$ pathway.

\section{Materials and methods}

Animals.In the present study, 7-week-old specific pathogen-free female BALB/c mice (weight, 18-22 g) purchased from Beijing Vital River Laboratory Animal Technology Co., Ltd. Mice were housed under standard laboratory conditions at $25^{\circ} \mathrm{C}$ with $50 \pm 5 \%$ humidity and 12 -h light/dark cycles in the experimental animal center of the Plastic Surgery Hospital (Chinese Academy of Medical Sciences and Peking Union Medical College; Beijing, China) for 1 week prior to the start of the experiments The animals were provided with sterilized food and water ad libitum. All experimental procedures were performed according to the People's Republic of China Animal Protection Law. Experimental animals were handled under a protocol approved by the Institutional Animal Care and Use Committee of Plastic Surgery Hospital, Chinese Academy of Medical Sciences and Peking Union Medical College.

Experimental protocols. A total of 30 female BALB/c mice were divided into six groups ( $\mathrm{n}=5 \mathrm{mice} / \mathrm{group}$ ): Control, OVA, OVA + DEX $(20,30$ or $50 \mu \mathrm{g} / \mathrm{kg})$ and OVA + TAK-242 (an inhibitor of TLR4) groups. All mice except those in the control group were sensitized on days 1, 7 and 14 with an intraperitoneal (i.p.) injection of $100 \mu \mathrm{g}$ ovalbumin (OVA; Sigma-Aldrich; Merck KGaA), $10 \mathrm{mg}$ aluminum hydroxide (Sigma-Aldrich; Merck KGaA) in saline (200 $\mu 1)$. The control group was injected with $200 \mu \mathrm{l}$ saline. From day 21 to 29, the mice in the OVA + DEX (Jiangsu Hengrui Medicine Co., Ltd.) groups received daily i.p. injections of 20,30 or $50 \mu \mathrm{g} / \mathrm{kg} \mathrm{DEX}$, and those in the OVA + TAK-242 (MedChemExpress) group received $3 \mathrm{mg} / \mathrm{kg}$ TAK-242 daily i.p. injection; these mice were also challenged by intranasal administration of $200 \mu \mathrm{g}$ OVA in $30 \mu \mathrm{l}$ saline $60 \mathrm{~min}$ after the i.p. injection. From day 21 to 29, the control group was intranasally administered $30 \mu 1$ saline once a day, and each OVA group received a daily intranasal administration of $200 \mu \mathrm{g}$ OVA in $30 \mu \mathrm{l}$ saline. The mice were sacrificed $24 \mathrm{~h}$ after the last challenge. After airway resistance measurement, the mice were euthanized using an i.p. administered overdose of $2 \%$ pentobarbital sodium $(150 \mathrm{mg} / \mathrm{kg})$; bronchoalveolar lavage fluid (BALF) and lung tissue were then collected.

Histological analysis of lung tissue. Following BALF collection, lung tissue samples were fixed at room temperature with $4 \%$ paraformaldehyde for $48 \mathrm{~h}$, then embedded in paraffin. A series of $5-\mu \mathrm{m}$ thick lung sections were prepared for hematoxylin and eosin (H\&E) and periodic acid-Schiff (PAS) staining (Beijing Solarbio Science \& Technology Co., Ltd.). The slides were deparaffinized in xylene and rehydrated in descending alcohol solutions. H\&E staining was performed at room temperature to assess inflammatory cell infiltration. Briefly, cells were stained with hematoxylin for $1 \mathrm{~min}$, washed with tap water five times, incubated with blue nuclei in $1 \mathrm{X}$ PBS for $1 \mathrm{~min}$, washed three times with distilled water, counterstained in alcoholic-eosin for $1 \mathrm{~min}$ and then dehydrated using an ascending alcohol series. Subsequently, xylene clearing was performed. PAS staining was performed at room temperature to assess goblet cell hyperplasia. Following oxidization in $0.5 \%$ periodic acid solution for $6 \mathrm{~min}$ and rinsing with distilled water, the slides were covered by Schiff regent for $15 \mathrm{~min}$, washed with tap water for $5 \mathrm{~min}$, stained with hematoxylin for $50 \mathrm{sec}$, rinsed with running water for $2 \mathrm{~min}$ and then differentiated with hydrochloric acid for $3 \mathrm{sec}$. The percentage of PAS-stained cells in the airway epithelium is indicative of the production of mucus (22). A total of five fields of view were examined by two experienced pathologists blindly at x200 magnification using a BX53 upright fluorescence microscope (Olympus Corporation) under the mode of bright-field imaging. The evaluation of peribronchial inflammation was based on a modified six-point scoring system (23) as follows: 0, normal; 1 , a few cells; 2 , a ring of inflammatory cells consisting of one cell layer; 3 , a ring of inflammatory cells consisting of two-four cell layers; 4, a ring of inflammatory cells consisting of five-seven cell layers; 5, a ring of inflammatory cells consisting of eight-ten cell layers; 6 , a ring of inflammatory cells consisting of $>10$ cell layers. A modified scoring system (24) was used for the abundance of PAS-positive mucus-containing cells in each airway as follows: $0,<2 \% ; 1, \geq 2 \%$ and $<20 \% ; 2, \geq 20 \%$ and $<40 \% ; 3, \geq 40 \%$ and $<60 \% ; 4, \geq 60 \%$ and $<80 \%$; and $5, \geq 80 \%$ PAS-positive cells.

Analysis of BALF. The mice were anaesthetized with $2 \%$ pentobarbital sodium $(150 \mathrm{mg} / \mathrm{kg}) 24 \mathrm{~h}$ after the last challenge. After inserting a catheter into the trachea, the lungs were flushed with $0.8 \mathrm{ml}$ cold PBS three times, and $85-95 \%$ of the lavage volume was collected through the catheter. BALF was centrifuged at $187 \mathrm{x} \mathrm{g}$ at $4^{\circ} \mathrm{C}$ for $10 \mathrm{~min}$. The supernatant was collected and stored at $-80^{\circ} \mathrm{C}$ until analyzed by ELISA. The total count of inflammatory cells in the BALF was determined using a chamber slide and the eosinophil counts were determined using ImageJ software (version 1.8.0; National Institutes of Health) by Wright-Giemsa staining (Beijing Solarbio Science \& Technology Co., Ltd.) at room temperature for $1.5 \mathrm{~min}$.

ELISA. Commercial ELISA kits (IL-4, cat. no. EK0405; IL-5, cat. no. EK0408; and IL-13, cat. no. EK0425; all from Boster Biological Technology) were used to detect the levels of IL-4, IL-5 and IL-13 in BALF according to the 
manufacturer's protocol. The optical density was spectrophotometrically measured at $450 \mathrm{~nm}$ using a multimode plate reader (PerkinElmer, Inc.).

Assessment of AHR. AHR was detected $24 \mathrm{~h}$ after the last challenge. The mice were anesthetized with $2 \%$ pentobarbital sodium $(50 \mathrm{mg} / \mathrm{kg})$ and the airway resistance was measured using FlexiVent (SCIREQ). Aerosolized methacholine (Mch) at different concentrations $(0,6,12,24$ and $48 \mathrm{mg} / \mathrm{ml})$ was continuously nebulized through a catheter in each animal for $6 \mathrm{~min}$. The airway resistance was collected every minute and the final result of each concentration for each animal was presented as the average of $6 \mathrm{~min}$. The airway resistance is presented as respiratory resistance ( $\mathrm{Rrs}$ ) in $\mathrm{cmH}_{2} \mathrm{O} / \mathrm{ml} / \mathrm{sec}$. The results are presented as the percentage increase in Rrs at each concentration of Mch over the baseline (Rrs in the control mice at different concentrations of Mch).

Reverse transcription-quantitative PCR (RT-qPCR). Total RNA was extracted from homogenized lung tissue $(50 \mathrm{mg})$ using TRIzol ${ }^{\circledast}$ (Ambion; Thermo Fisher Scientific, Inc.) according to the manufacturer's protocol. The RNA pellet was resuspended in DNase/RNase-free water (Beijing Solarbio Science \& Technology Co., Ltd.). RNA concentration was measured at a wavelength of $260 \mathrm{~nm}$ using a NanoDrop ${ }^{\circledR} 2000$ ultraviolet spectrophotometer (Thermo Fisher Scientific, Inc.), and the quality of RNA was evaluated by verifying that the ratio at 260/280 nm was 1.8-2.0. RT was carried out with $5 \mu \mathrm{g}$ RNA using the TransScript ${ }^{\circledR}$ First-Strand cDNA Synthesis SuperMix (Beijing Transgen Biotech Co., Ltd.) in 20- $\mu 1$ reaction volumes, according to the manufacturer's protocol. The qPCR primers (Invitrogen; Thermo Fisher Scientific, Inc.) were as follows: IL-4 forward, 5'-CTCACAGCAACGAAGAAC ACC-3' and reverse, 5'-CTGCAGCTCCATGAGAACACT-3'; IL-5 forward, 5'-AGA ATCAAACTGTCCGTGGGG-3' and reverse, 5'-TCCTCGCCACACTTCTCTTTT-3'; IL-13 forward, 5'-CTCTTGCTTGCCTTGGTGGTC-3' and reverse, 5'-TGTGATGTTGCTCAGCTCCTC-3'; TLR4 forward, 5'-TCATCAGTGTATCGGTGGTCAG-3' and reverse, 5'-TTT CCATCCAACAGGGCTTT-3'; NF- $\kappa$ B forward, 5'-GGGGCC TGCAAAGGTTATC-3' and reverse, 5'-TGCTGTTACGGT GCATACCC-3'; and $\beta$-actin forward, 5'-CTCTTTTCCAGC CTTCCTTCTT-3' and reverse, 5'-AGGTCTTTACGGATGT CAACGT-3'. The relative expression levels of the IL-4, IL-5, IL-13, TLR4 and NF- $\kappa B$ end-products were normalized to those of $\beta$-actin. qPCR was carried out using LightCycler ${ }^{\circledR}$ 480 SYBR Green I Master mix (Roche Diagnostics GmbH) on a LightCycler ${ }^{\circledR} 96$ Instrument (Roche Diagnostics GmbH). The following thermocycling conditions were used for qPCR: Initial denaturation at $95^{\circ} \mathrm{C}$ for $180 \mathrm{sec}$; followed by a two-step amplification of 40 cycles of denaturation at $95^{\circ} \mathrm{C}$ for $10 \mathrm{sec}$ and extension at $60^{\circ} \mathrm{C}$ for $30 \mathrm{sec}$. The data were analyzed using the $2^{-\Delta \Delta C q}$ method (25) and LightCycler ${ }^{\circledR} 96$ software version 1.1 (Roche Diagnostics $\mathrm{GmbH}$ ).

Immunohistochemistry. Paraffin-embedded lung tissue blocks were cut into 5- $\mu \mathrm{m}$ sections, which were used for TLR4, NF- $\mathrm{kB}$ and phosphorylated (p)NF- $\mathrm{kB}$ protein detection. For immunohistochemical staining, the anti-TLR4 (cat.no. K003881P; 1:100) and anti-NF- $\mathrm{KB}$ (cat. no. K003592P; 1:50) primary antibodies and the SABC (Rabbit IgG)-POD kit (cat. no. SA0021) were obtained from Beijing Solarbio Science \& Technology Co. Ltd. Anti-p-NF-кB (cat. no. 3033T; 1:100) primary antibody was obtained from Cell Signaling Technology, Inc. The slides were deparaffinized in xylene and rehydrated in a descending alcohol series, and the endogenous peroxidase activity was quenched at room temperature for $8 \mathrm{~min}$ using $0.3 \%$ hydrogen peroxide. The sections were boiled in $0.01 \mathrm{~mol} / 1$ sodium citrate buffer $(\mathrm{pH}$ 6.0) in a microwave oven for $12 \mathrm{~min}$ for antigen retrieval, then rinsed three times with PBS (pH 7.2-7.6) for 5 min. After blocking nonspecific protein binding with 5\% BSA (cat. no. P1621-25; Applygen Technologies, Inc.) at room temperature for $30 \mathrm{~min}$, the sections were incubated for $12 \mathrm{~h}$ with primary antibodies at $4{ }^{\circ} \mathrm{C}$. The sections were then incubated with biotinylated goat anti-rabbit IgG (cat. no. SE134; 1:100; Beijing Solarbio Science $\&$ Technology Co., Ltd.) for $60 \mathrm{~min}$ at room temperature, and all the results were detected with DAB chromogenic solution at room temperature for 4-5 min. After rinsing three times with PBS (pH 7.2-7.6) for $5 \mathrm{~min}$, the slides were stained at room temperature with hematoxylin for $50 \mathrm{sec}$, rinsed with running water for $2 \mathrm{~min}$, differentiated with hydrochloric acid for $3 \mathrm{sec}$. The percentage of positively stained area was calculated by two independent pathologists using ImageJ software and the IHC Profiler plugin (version 1.8.0; National Institutes of Health).

Statistical analysis. The experiments were performed independently three times. Quantitative data are presented as the mean \pm SD and were analyzed using one-way ANOVA followed by Bonferroni's multiple comparisons test. Ordinal data are presented as the median + interquartile range and were analyzed using Kruskal-Wallis followed by Dunn's multiple comparisons test. Graphs were generated and data were analyzed using GraphPad Prism (version 6; GraphPad Software, Inc.). P $<0.05$ was considered to indicate a statistically significant difference.

\section{Results}

$D E X$ reduces $A H R$ and inflammatory cell infiltration in $B A L F$. To assess the effect of DEX on inflammatory cell infiltration in the airway, the number of inflammatory cells in BALF was analyzed. Compared with the control group, the number of total cells and eosinophils in BALF were significantly increased in the OVA group (Fig. 1A and B). However, the number of total cells and eosinophils in the OVA + DEX (30 and $50 \mu \mathrm{g} / \mathrm{kg}$ ) groups were reduced compared with the OVA group, whereas pretreatment with DEX at $20 \mu \mathrm{g} / \mathrm{kg}$ did not decrease the number of eosinophils (Fig. 1B). The dose of $30 \mu \mathrm{g} / \mathrm{kg}$ DEX (DEX30) resulted in the largest decrease.

Compared with the control group, the mice that received OVA alone exhibited increased Rrs in response to inhaled Mch at all concentrations. Compared with the OVA group, the various DEX treatments significantly reduced Rrs. The OVA + DEX30 group exhibited the largest reduction in AHR (Fig. 1C).

These results suggested that treatment with DEX30 inhibited the recruitment of inflammatory cells in BALF and reduced AHR in a murine OVA-induced asthma model.

DEX alleviates airway inflammation and mucus overproduction. Since inflammatory cell recruitment and mucus overproduction are the main characteristics of allergic 

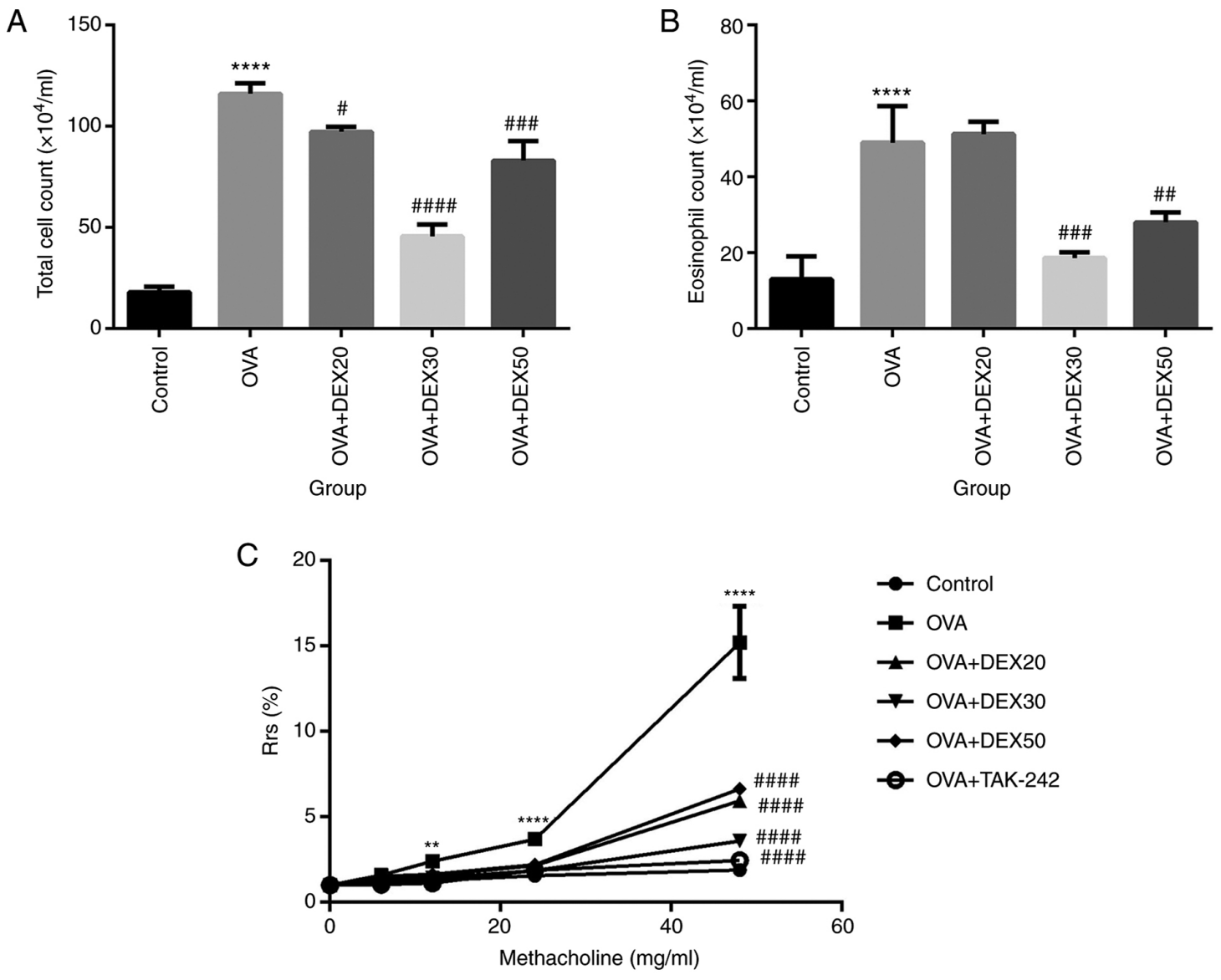

Figure 1. Effect of DEX on the infiltration of inflammatory cells in BALF and AHR. Number of (A) total cells and (B) eosinophils in BALF were measured by Wright-Giemsa staining. (C) AHR in OVA-induced asthmatic mice treated with DEX and TAK-242. Mice were nebulized with different concentrations of methacholine $(0,6,12,24$ and $48 \mathrm{mg} / \mathrm{ml})$. Results are presented as the percentage increase in Rrs over the baseline, and the baseline Rrs of the control group was defined as $100 \%$. Data are presented as the mean $\pm \mathrm{SD}(\mathrm{n}=3) .{ }^{* *} \mathrm{P}<0.01$ and ${ }^{* * * * *} \mathrm{P}<0.0001$ vs. control; ${ }^{*} \mathrm{P}<0.05,{ }^{\# \#} \mathrm{P}<0.01,{ }^{\# \# \#} \mathrm{P}<0.001$ and ${ }^{\# \# \# \#} \mathrm{P}<0.0001$ vs. OVA. AHR, airway hyperresponsiveness; BALF, bronchoalveolar lavage fluid; DEX, dexmedetomidine; OVA, ovalbumin; Rrs, respiratory resistance.

asthma (9), the subsequent experiments aimed to determine whether treatment with DEX could attenuate these symptoms. Inflammatory cell infiltration was assessed using $\mathrm{H} \& \mathrm{E}$ staining (Fig. 2A). Compared with the control group, lung tissue from mice in the OVA group exhibited a significantly higher number of inflammatory cells (Fig. 2B). However, treatment with DEX30 significantly inhibited inflammatory cell infiltration compared with the OVA group, and DEX at 20 and $50 \mu \mathrm{g} / \mathrm{kg}$ showed inhibitory effects on inflammatory infiltration, but these effects were not significant.

Mucus production in goblet cells was assessed using PAS staining. The percentage of PAS-positive cells in the OVA group was significantly higher than that of the control group, and treatment with DEX30 reduced the production of mucus in the airway compared with the OVA group, while pretreatment with DEX at 20 and $50 \mu \mathrm{g} / \mathrm{kg}$ displayed an inhibitory effect on mucus production that was not statistically significance (Fig. 2C and D). Thus, $30 \mu \mathrm{g} / \mathrm{kg}$ DEX could attenuate airway inflammation and mucus overproduction in the murine OVA-induced asthma model.

DEX inhibits the production of inflammatory cytokines in the murine OVA-induced asthma model. The levels of pro-inflammatory cytokines were detected in BALF from mice in the Control, OVA and OVA + DEX30 groups. As presented in Fig. 3, IL-4, IL-5 and IL-13 levels in the OVA group were significantly higher compared with those in the control group. However, treatment with DEX30 significantly reduced the levels of these cytokines compared with the OVA group.

Furthermore, the mRNA expression levels of IL-4, IL-5 and IL-13 in the lung tissue were also examined (Fig. 4). IL-4, IL-5 and IL-13 mRNA expression levels in the lung tissue of the OVA group were significantly higher compared with those of the control group. Treatment with DEX30 significantly decreased the levels of IL-4, IL-5 and IL-13 mRNA compared with the OVA group.

TAK-242 attenuates airway inflammation and AHR in asthma model mice. It was examined whether AHR and airway inflammation in the OVA-induced asthma model could be ameliorated by TAK-242. The i.p. injection of TAK-242 or DEX before OVA challenge reduced airway resistance in response to inhaled Mch (Fig. 1C), and reduced the total number of cells and eosinophils in the BALF (Fig. 5A). To examine the effect of TAK-242 on airway inflammation, H\&E and PAS staining were performed to detect inflammatory cell infiltration and the production of mucus in the lung, respectively. Administration of TAK-242 or DEX attenuated OVA-induced airway inflammation by 
A

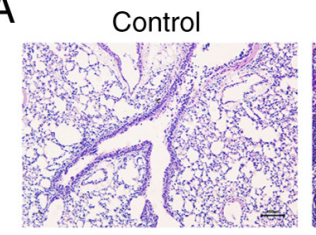

OVA+DEX20
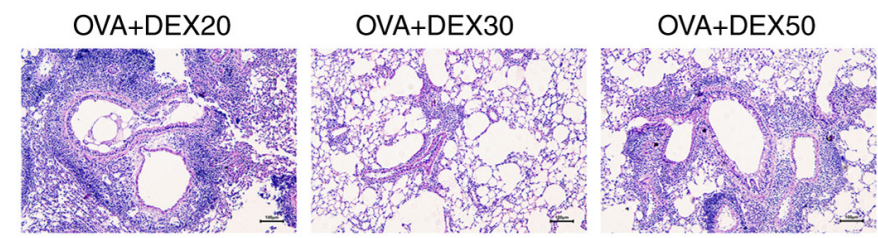

C

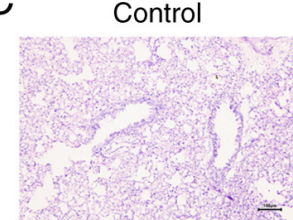

OVA+DEX20

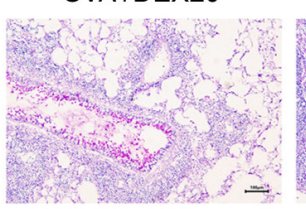

OVA

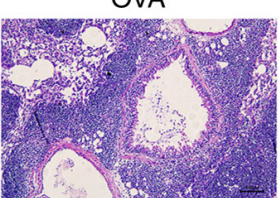

OVA+DEX30

OVA

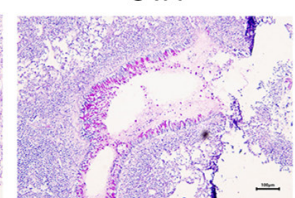

OVA+DEX30

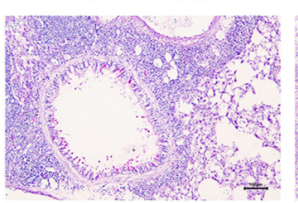

\section{OVA+DEX50}

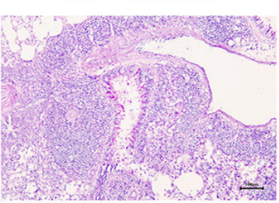

B
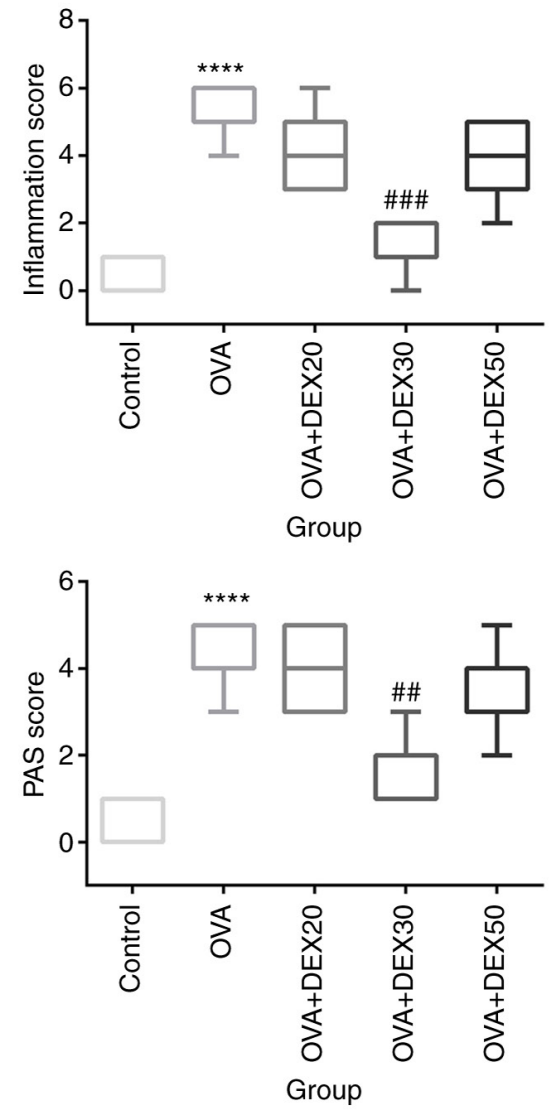

Figure 2. Effect of DEX on airway inflammation and mucus overproduction. (A) Lung tissues were stained with H\&E to evaluate inflammatory cell infiltration. (B) Histological scoring of inflammatory cell infiltration was based on the morphological structure. (C) PAS staining was used to evaluate mucus in the lung tissues. (D) Histological scoring of PAS-positive rate was based on the morphological structure. Magnification, x200; scale bar, $100 \mu \mathrm{m}$. Data are presented as the median + interquartile range $(\mathrm{n}=5)$. ${ }^{* * * *} \mathrm{P}<0.0001$ vs. control; ${ }^{\# \#} \mathrm{P}<0.01$ and ${ }^{\# \# \#} \mathrm{P}<0.001$ vs. OVA. DEX, dexmedetomidine; ns, not significant; OVA, ovalbumin; PAS, periodic acid-Schiff.
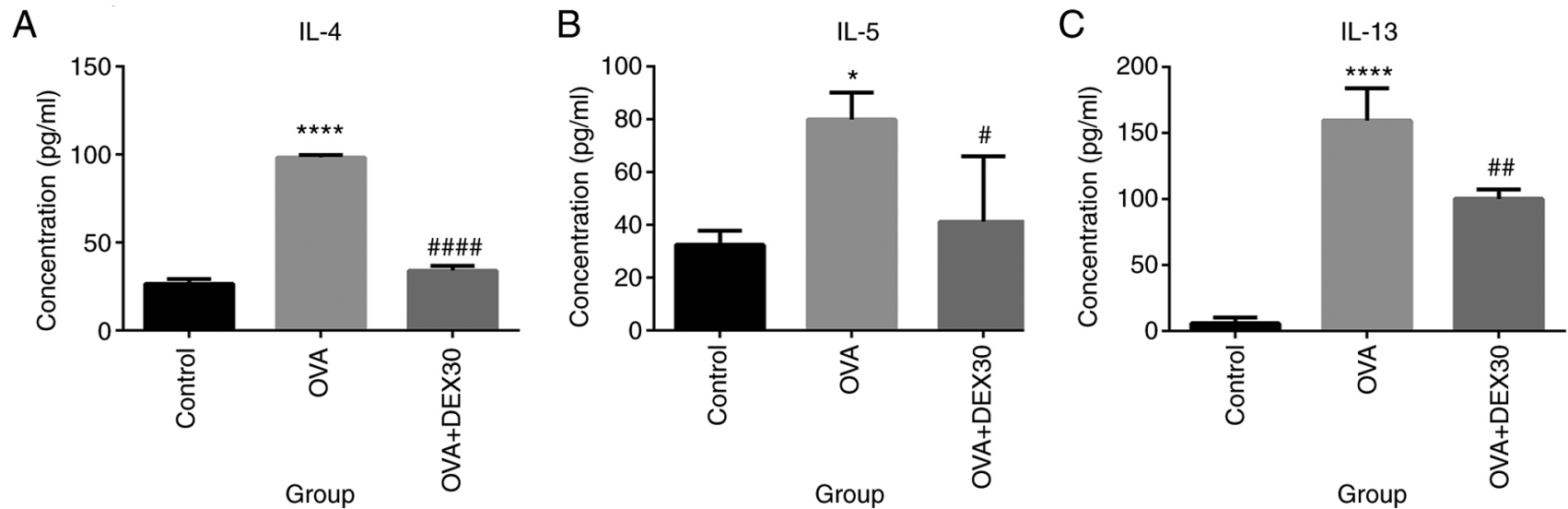

Figure 3. Effects of DEX on the level of IL-4, IL-5 and IL-13 in BALF. The levels of (A) IL-4, (B) IL-5 and (C) IL-13 in BALF were determined by ELISA. Data are presented as the mean $\pm \mathrm{SD}(\mathrm{n}=3)$. ${ }^{*} \mathrm{P}<0.05$ and ${ }^{* * * *} \mathrm{P}<0.0001$ vs. control; ${ }^{*} \mathrm{P}<0.05,{ }^{\# \#} \mathrm{P}<0.01$ and ${ }^{\# \# \# \#} \mathrm{P}<0.0001$ vs. OVA. BALF, bronchoalveolar lavage fluid; DEX, dexmedetomidine; OVA, ovalbumin.

reducing the number of infiltrating inflammatory cells in the airway (Fig. 5D and F) and the production of mucus (Fig. 5E and G). In addition, ELISA and RT-qPCR were used to assess pro-inflammatory cytokine levels in BALF and mRNA levels in the lung tissue, respectively. Both TAK-242 and DEX30 treated groups exhibited decreased levels of inflammatory cytokines in BALF (Fig. 5B) and lower expression levels of IL-4, IL-5 and IL-13 mRNA (Fig. 5C) in the lung tissue. These results indicated that the inhibitor of TLR4 (TAK-242) and DEX could alleviate the asthmatic symptoms in the murine OVA-induced asthma model to a similar extent. 

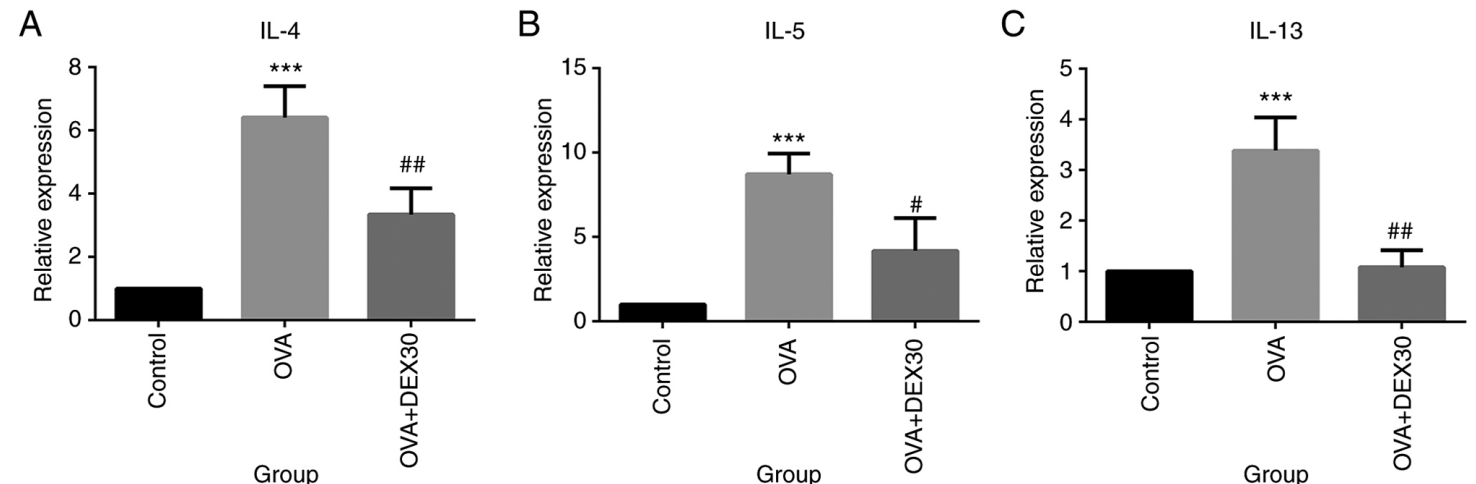

Figure 4. DEX downregulates the mRNA expression levels of inflammatory cytokines in the lung tissue. mRNA expression levels of (A) IL-4, (B) IL-5 and (C) IL-13 were determined by reverse transcription-quantitative PCR. Data are presented as the mean $\pm \mathrm{SD}(\mathrm{n}=3)$. ${ }^{* * *} \mathrm{P}<0.001 \mathrm{vs}$. control; ${ }^{*} \mathrm{P}<0.05$ and ${ }^{\#} \mathrm{P}<0.01$ vs. OVA. DEX, dexmedetomidine; OVA, ovalbumin.
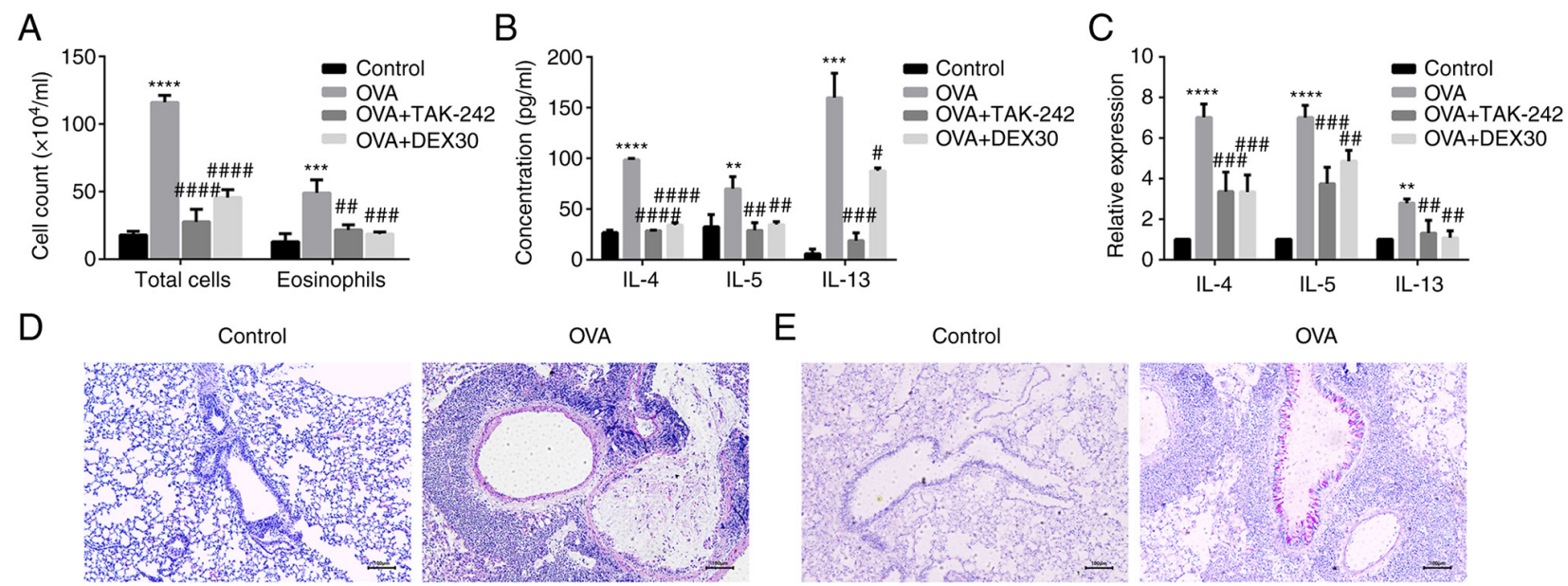

$\mathrm{E}$

Control

OVA

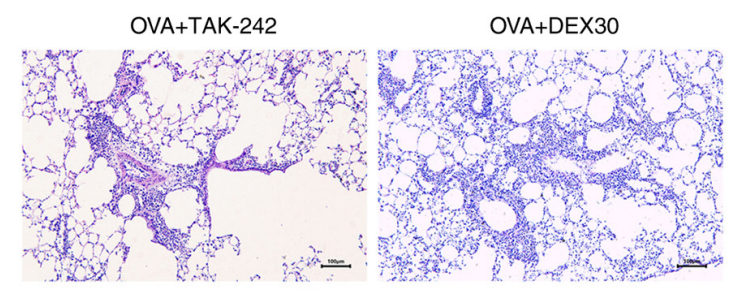

$\mathrm{F}$
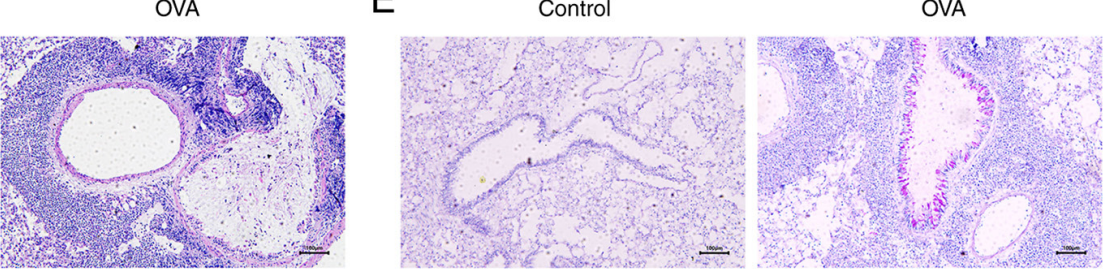

OVA+TAK-242

OVA+DEX30

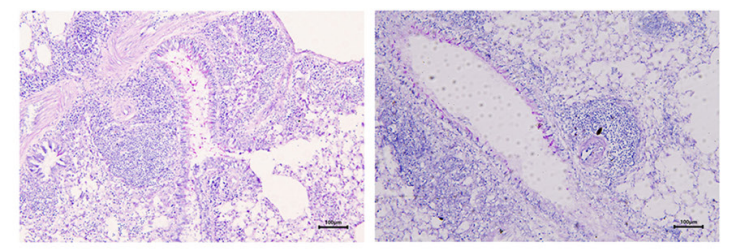

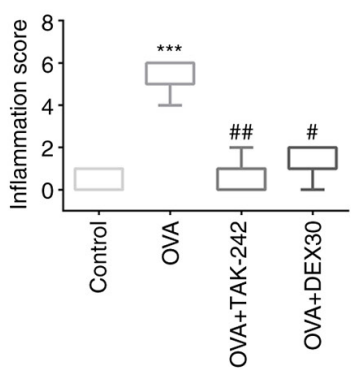

G

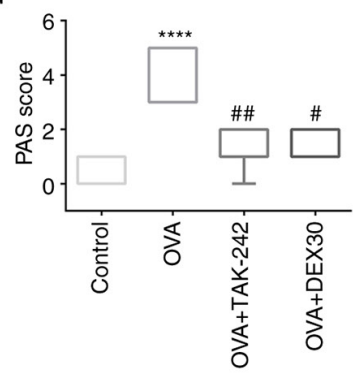

Figure 5. Effect of TAK-242 and DEX on the infiltration of inflammatory cells in BALF, and inflammatory cytokine expression and histological analysis of lung tissues. (A) Number of total cells and eosinophils in BALF were measured by Wright-Giemsa staining. (B) Concentrations of IL-4, IL-5 and IL-13 in BALF were determined by ELISA. (C) Gene expression levels of IL-4, IL-5 and IL-13 in the lung tissues were evaluated by reverse transcription-quantitative PCR. (D) Lung sections were stained with H\&E to evaluate inflammatory cells. (E) PAS staining was used to evaluate mucus in the lung tissues. (F) Histological scoring of inflammatory cell infiltration was based on the morphological structure. (G) Histological scoring of PAS-positive rate was based on the morphological structure. Magnification, $\mathrm{x} 200$; scale bar, $100 \mu \mathrm{m}$. Quantitative data are presented as the mean \pm SD $(\mathrm{n}=3$ ), and ordinal data are presented

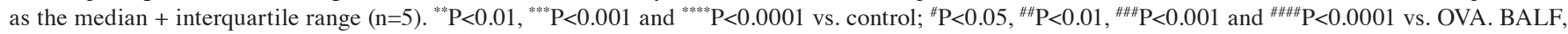
bronchoalveolar lavage fluid; DEX, dexmedetomidine; OVA, ovalbumin; PAS, periodic acid-Schiff.

DEX inhibits the TLR4/NF- $\kappa B$ pathway. TLR4 and NF- $\mathrm{KB}$ serve an important role in inflammatory responses by promoting the transcription of various pro-inflammatory cytokines (26). Immunohistochemistry was performed to 
A
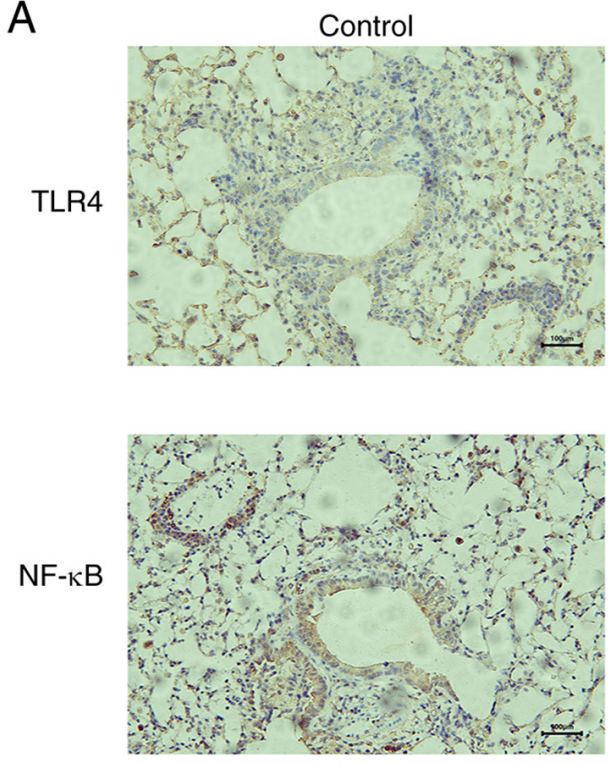

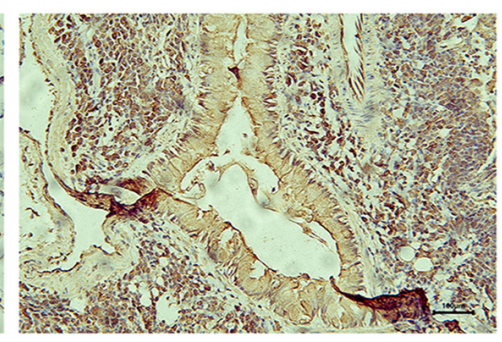

OVA

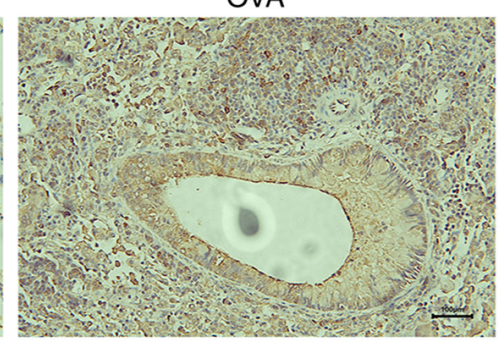

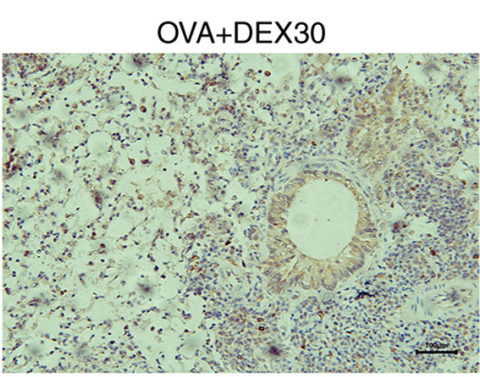

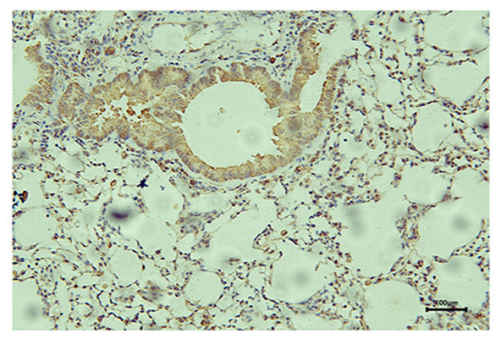

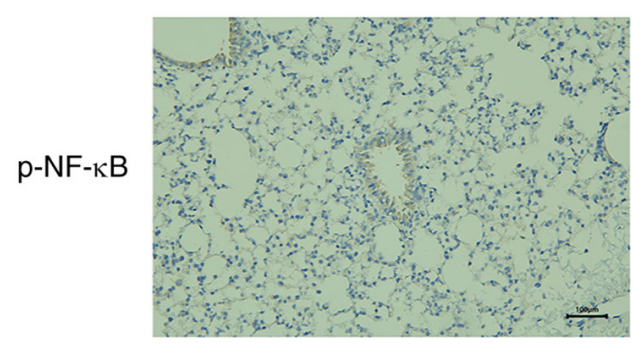

$\mathrm{B}$

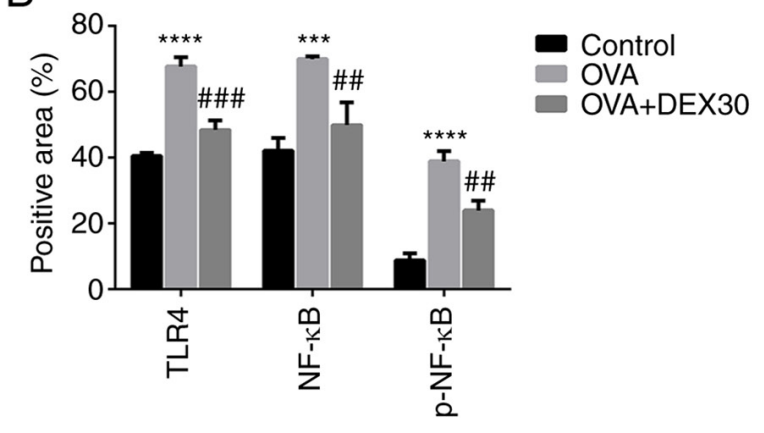

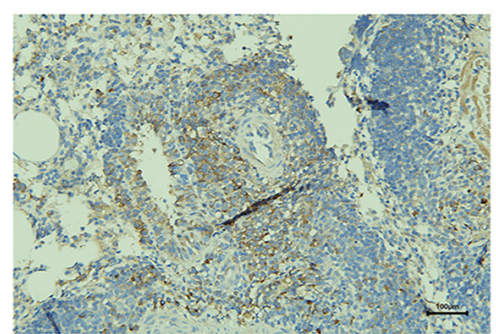

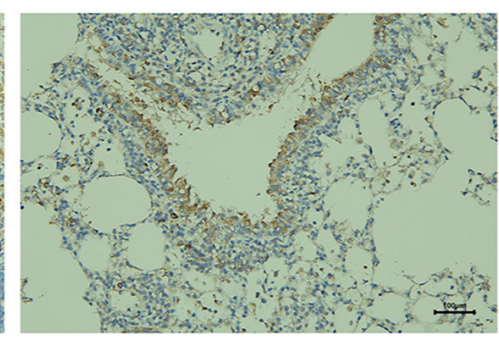

C

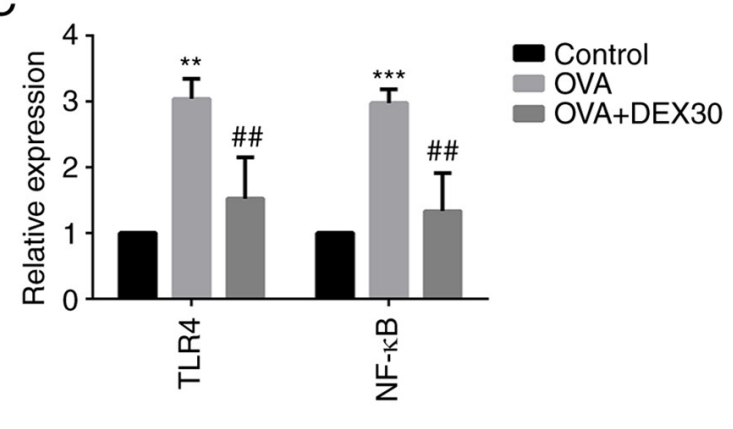

Figure 6. Effect of DEX on the expression of TLR4, NF- $\kappa$ B and p-NF- $\kappa$ B. (A) Representative immunohistochemistry images and (B) quantification of TLR4, NF- $\kappa \mathrm{B}$ and $\mathrm{p}-\mathrm{NF}-\kappa \mathrm{B}$ expression; results are presented as positive area percentage. Magnification, $\mathrm{x} 200$; scale bar, $100 \mathrm{~m}$. (C) mRNA expression levels of TLR4 and NF- $\mathrm{B}$ were examined by reverse transcription-quantitative $\mathrm{PCR}$. Data are presented as the mean $\pm \mathrm{SD}\left(\mathrm{n}=3\right.$ ). ${ }^{* *} \mathrm{P}<0.01,{ }^{* * *} \mathrm{P}<0.001$ and ${ }^{* * * * *} \mathrm{P}<0.0001$ vs. control; ${ }^{\# \#} \mathrm{P}<0.01$ and ${ }^{\# \# \#} \mathrm{P}<0.001$ vs. OVA. DEX, dexmedetomidine; IHC, immunohistochemistry; OVA, ovalbumin; p, phosphorylated; TLR4, toll-like receptor 4.

detect the expression of TLR4, NF- $\mathrm{B}$ and $\mathrm{p}-\mathrm{NF}-\kappa \mathrm{B}$ in the lung tissue. As shown in Fig. 6A and B, the expression of TLR4, NF- $\kappa B$ and $p-N F-\kappa B$ was increased in the OVA group compared with the control group, whereas DEX at $30 \mu \mathrm{g} / \mathrm{kg}$ significantly downregulated the expression level of TLR4, $N F-\kappa B$ and $p-N F-\kappa B$ in the lung tissue of the asthmatic mice. The expression levels of TLR4 and NF- $\kappa B$ mRNA were also determined by RT-qPCR (Fig. 6C). The mRNA expression of TLR4 and NF- $\mathrm{KB}$ in the lung tissue from the OVA group was elevated, and DEX significantly downregulated their levels. The aforementioned results suggested that DEX may inhibit the activation of the TLR4/NF- $\mathrm{KB}$ pathway.

\section{Discussion}

AHR is a characteristic of asthma that has emerged as a major challenge in the perioperative management of asthmatic patients (27). AHR can be a life-threatening symptom for patients with asthma during the perioperative period, as it can result in hypoventilation, hypoxemia and cardiac arrhythmia. The perioperative management of asthmatic patients includes the following: i) Detection of upper airway infection prior to surgery; ii) appropriate choices of anesthesia; and iii) $\beta-2$ adrenergic agonist treatment in the case of acute attacks (28). Certain anesthetic agents can dilate the airway, whereas others can also induce bronchoconstriction (29). Therefore, 
it is essential to select appropriate anesthetic agents that will benefit the patient.

DEX is an anesthetic adjuvant reported to attenuate perioperative inflammation and improve the immune function of patients who have undergone surgery (18). Groeben et al (30) reported that intravenous administration of DEX attenuated bronchoconstriction in dogs treated with histamine. It was clinically observed that patients who had received DEX exhibited reduced airway resistance during mechanical ventilation (31) in surgery and hemodynamic stability during extubation (32). In the present study, an OVA-induced murine asthma model was used to examine the effect of DEX on allergic asthma. TAK-242, a TLR4 inhibitor, was used to determine whether DEX could affect TLR4 signaling. To the best of our knowledge, the present study is the first to demonstrate the inhibitory effect of DEX on allergic airway inflammation in mice.

According to the dose choices of previous studies on the role of DEX in inflammatory diseases, most working doses in mice were in the $20-50 \mu \mathrm{g} / \mathrm{kg}$ range [5, 10 and $20 \mu \mathrm{g} / \mathrm{kg}(33)$; $25 \mu \mathrm{g} / \mathrm{kg}(34) ; 2$ and $50 \mu \mathrm{g} / \mathrm{kg}(21)]$, and the safety of DEX at $200 \mu \mathrm{g} / \mathrm{kg}$ i.p. in BALB/c mice has been demonstrated (35). To further narrow down the range, a dose-response experiment with different concentrations of DEX (10, 20, 30, 40, 50 and $60 \mu \mathrm{g} / \mathrm{kg}$ ) was performed (data not shown). According to the cell counts and Rrs results, 20,30 and $50 \mu \mathrm{g} / \mathrm{kg}$ were used in the present study.

Increasing infiltration of leukocytes around the airway, particularly eosinophils, is one of the main factors in the pathogenesis of asthma (36). The present study demonstrated that DEX effectively decreased inflammatory cell infiltration in the airway and inhibited mucus overproduction in OVA-induced asthmatic mice. This indicated that DEX may suppress inflammatory responses in the lungs of asthmatic patients.

The imbalance of Th1/Th2 cells is pivotal in promoting the development of asthma; indeed, the Th2 phenotype is predominant, and the activity of Th1 cells is suppressed in allergic asthma (37). Activated Th2 cells can release type- 2 cytokines, such as IL-4, IL-5 and IL-13, which promotes the development of asthma, including AHR, mucus overproduction and eosinophil infiltration (9). The present study revealed that treatment with DEX reduced the levels of IL-4, IL-5 and IL-13 in BALF of asthmatic mice. Thus, it was demonstrated that DEX may attenuate airway inflammation in asthmatic mice by suppressing the Th2 immune response.

AHR is a typical symptom of asthma that can also be associated with behavioral changes in mice (38). In the present study, following intranasal administration of OVA, mice in the OVA group were more irritated and exhibited an elevated respiratory rate, compared with the OVA + DEX group. In the present study, cyanosis was also observed in the OVA group (data not shown). These behavioral changes may be associated with AHR owing to a limited airflow (39). The mechanism of AHR remains unclear, although a previous study demonstrated a close association between inflammatory cytokines and the development of AHR (40). The results of the present study demonstrated that DEX may effectively relieve inflammation in the lungs and attenuate OVA-induced AHR in response to inhaled Mch.
It has been suggested that the activation of the TLR4/NF- $\kappa \mathrm{B}$ pathway can promote the infiltration of inflammatory cells in the airway and trigger airway inflammation (41). Although strong evidence that the $\alpha$-adrenergic receptor is associated with TLR4/NF- $\kappa \mathrm{B}$ signaling is still lacking, several studies have indicated that DEX can protect organ function by inhibiting TLR4 signaling $(14,30,31)$. The TLR4/NF- $\kappa$ B signaling pathway has also been associated with the anti-inflammatory effects of DEX (42). Activated NF- $\kappa \mathrm{B}$ p65 is phosphorylated, then translocated into the nucleus to promote the transcription of target genes encoding inflammatory cytokines, which contribute to the pathogenesis of asthmatic airway inflammation (43). The present results indicated that DEX inhibited the activation of NF- $\kappa \mathrm{B}$ by reducing the expression of $\mathrm{NF}-\kappa \mathrm{B}$ p65 and TLR4 in OVA-induced asthmatic mice. Thus, DEX may attenuate airway inflammation in the OVA-induced asthma model by suppressing the activation of the TLR4/NF- $\kappa \mathrm{B}$ pathway.

How DEX affects the TLR4 pathway has not been fully determined, although it has been demonstrated that microRNA (miRNA/miR) and long non-coding (lnc)RNAs may serve a role in this context. miRNAs serve crucial roles in regulating various signaling pathways, such as miR-30 regulates the MAPK/KRAS pathway (44), miR-486 regulates the PI3K/AKT pathway (45) and miR-340-5p regulates the PI3K/AKT pathway (46). Administration of DEX alters the level of several miRNA molecules in certain murine disease models, such as neuroinflammation (47), myocardial ischemia/reperfusion (48) and postoperative cognitive dysfunction (49). In addition, it has been reported that DEX can inhibit the NF- $\kappa$ B pathway by regulating miR-146a-3p (48) and the TLR4 pathway via the regulation of miR-129 (49). In addition to miRNAs, lncRNAs are also involved in several diseases through DEX, such as chronic obstructive pulmonary disease (50), postoperative cognitive dysfunction (51) and oxygen-glucose deprivation/reperfusion injury (52). Thus, it may be hypothesized that miRNAs or lncRNAs could mediate the effect of DEX on TLR4/NF- $\mathrm{B}$ signaling.

In the present study, DEX treatment at $30 \mu \mathrm{g} / \mathrm{kg}$ resulted in an improved therapeutic effect compared with treatment with a higher concentration $(50 \mu \mathrm{g} / \mathrm{kg})$, suggesting that there may be a dose limit to the therapeutic effect of DEX in the murine OVA-induced allergic asthma model. Doses higher than the $30 \mu \mathrm{g} / \mathrm{kg}$ limit may result in reduced therapeutic effect causing unexpected results, such as worsening symptoms or other side effects. This dose limit may also differ between mouse strains, administration mode and other factors.

DEX may be a safer choice as a sedative and an anesthetic adjunct in patients with acute asthma. Acute asthma attack causes anxiety and agitation in patients, which hinders treatment and adversely affects patients (53). DEX allows patients to rest and increase their tolerance to treatment without respiratory depression. It is also used as adjunctive treatment for acute and severe asthma $(53,54)$. DEX has been used to facilitate the induction of noninvasive positive pressure ventilation for acute respiratory failure in patients with severe asthma (53) and in monitoring anesthesia care for bronchial thermoplasty (54).

In conclusion, the present study demonstrated that DEX attenuated AHR and airway inflammation by decreasing 
the production of type- 2 cytokines through the inhibition of TLR4/NF- $\kappa$ B signaling in a murine OVA-induced asthma model. These findings suggested that DEX may represent an alternative choice for the perioperative management of patients with asthma and a potential anti-inflammatory anesthetic.

\section{Acknowledgements}

Not applicable.

\section{Funding}

The present study was supported by the Plastic Surgery Hospital, Chinese Academy of Medical Sciences and Peking Union Medical College (Beijing, China) (grant no. YS202006). Funding was provided for various projects in the experiment, including model establishment, experimental drugs and equipment.

\section{Availability of data and materials}

The datasets used and/or analyzed during the current study are available from the corresponding author on reasonable request.

\section{Authors' contributions}

QW analyzed and interpreted the data and designed the study. SX drafted the manuscript and critically revised it for important intellectual content. QW, SX, XZ and HG performed the experiments. JZ and DY made substantial contributions to the study conception. QW and SX confirmed the authenticity of all the raw data. DY gave final approval of the version to be published. All authors have read and approved the final manuscript.

\section{Ethics approval and consent to participate}

Experimental animals were handled under a protocol approved by the Institutional Animal Care and Use Committee of Plastic Surgery Hospital, Chinese Academy of Medical Sciences and Peking Union Medical College (approval no. 2021(201); Beijing, China).

\section{Patient consent for publication}

Not applicable.

\section{Competing interests}

The authors declare that they have no competing interests.

\section{References}

1. Papi A, Brightling C, Pedersen SE and Reddel HK: Asthma. Lancet 391: 783-800, 2018.

2. Kong S, So WY and Jang S: The association between vigorous physical activity and stress in adolescents with asthma. Int J Environ Res Public Health 18: 3467, 2021.

3. Vasileiadou S, Ekerljung L, Bjerg A and Goksör E: Asthma increased in young adults from 2008-2016 despite stable allergic rhinitis and reduced smoking. PLoS One 16: e0253322, 2021.
4. Loftus PA and Wise SK: Epidemiology and economic burden of asthma. Int Forum Allergy Rhinol 5 (Suppl 1): S7-S10, 2015.

5. Woods BD and Sladen RN: Perioperative considerations for the patient with asthma and bronchospasm. Br J Anaesth 103 (Suppl 1): i57-i65, 2009.

6. Buendía JA and Patiño DG: Cost-utility of triple versus dual inhaler therapy in moderate to severe asthma. BMC Pulm Med 21: 398, 2021

7. Facchinetti F, Civelli M, Singh D, Papi A, Emirova A and Govoni M: Tanimilast, A Novel Inhaled Pde4 inhibitor for the treatment of asthma and chronic obstructive pulmonary disease. Front Pharmacol 12: 740803, 2021.

8. Hall S and Agrawal DK: Key mediators in the immunopathogenesis of allergic asthma. Int Immunopharmacol 23: 316-329, 2014.

9. Lambrecht BN, Hammad $\mathrm{H}$ and Fahy JV: The cytokines of asthma. Immunity 50: 975-991, 2019.

10. Nagase H, Ueki S and Fujieda S: The roles of IL-5 and anti-IL-5 treatment in eosinophilic diseases: Asthma, eosinophilic granulomatosis with polyangiitis, and eosinophilic chronic rhinosinusitis. Allergol Int 69: 178-186, 2020.

11. Bagnasco D, Ferrando M, Varricchi G, Passalacqua G and Canonica GW: A Critical Evaluation of Anti-IL-13 and Anti-IL-4 strategies in severe asthma. Int Arch Allergy Immunol 170: 122-131, 2016.

12. Kim G, Hong M, Kashif A, Hong Y, Park BS, Mun JY, Choi H, Lee JS, Yang EJ, Woo RS, et al: Der f 38 Is a Novel TLR4-binding allergen related to allergy pathogenesis from dermatophagoides farinae. Int J Mol Sci 22: 8440, 2021.

13. Lu X, Xu C, Yang R and Zhang G: Ganoderic acid a alleviates ova-induced asthma in mice. Inflammation 44: 1908-1915, 2021.

14. Kuzmich NN, Sivak KV, Chubarev VN, Porozov YB, Savateeva-Lyubimova TN and Peri F: TLR4 signaling pathway modulators as potential therapeutics in inflammation and sepsis. Vaccines (Basel) 5: 34, 2017.

15. Helal MG, Megahed NA and Abd Elhameed AG: Saxagliptin mitigates airway inflammation in a mouse model of acute asthma via modulation of NF-kB and TLR4. Life Sci 239: 117017, 2019.

16. Di Stefano A, Ricciardolo LFM, Caramori G, Adcock IM, Chung KF, Barnes PJ, Brun P, Leonardi A, Andò F, Vallese D, et al: Bronchial inflammation and bacterial load in stable COPD is associated with TLR4 overexpression. Eur Respir J 49: 1602006, 2017

17. Garantziotis S, Li Z, Potts EN, Lindsey JY, Stober VP, Polosukhin VV, Blackwell TS, Schwartz DA, Foster WM and Hollingsworth JW: TLR4 is necessary for hyaluronan-mediated airway hyperresponsiveness after ozone inhalation. Am J Respir Crit Care Med 181: 666-675, 2010.

18. Wang $\mathrm{K}, \mathrm{Wu} \mathrm{M}, \mathrm{Xu} \mathrm{J}$, Wu C, Zhang B, Wang G and Ma D: Effects of dexmedetomidine on perioperative stress, inflammation, and immune function: Systematic review and meta-analysis. Br J Anaesth 123: 777-794,2019.

19. Bao N and Tang B: Organ-protective effects and the underlying mechanism of dexmedetomidine. Mediators Inflamm 2020: 6136105,2020

20. Heil LB, Santos CL, Santos RS, Samary CS, Cavalcanti VC, Araújo MM, Poggio H, Maia Lde A, Trevenzoli IH, Pelosi P, et al: The effects of short-term propofol and dexmedetomidine on lung mechanics, histology, and biological markers in experimental obesity. Anesth Analg 122: 1015-1023, 2016.

21. Meng L, Li L, Lu S, Li K, Su Z, Wang Y, Fan X, Li X and Zhao G: The protective effect of dexmedetomidine on LPS-induced acute lung injury through the HMGB1-mediated TLR4/NF- $\kappa \mathrm{B}$ and PI3K/Akt/mTOR pathways. Mol Immunol 94: 7-17, 2018.

22. Wang S, Jiang Z, Li L, Zhang J, Zhang $\mathrm{C}$ and Shao C: Ameliorative effects of eosinophil deficiency on immune response, endoplasmic reticulum stress, apoptosis, and autophagy in fungus-induced allergic lung inflammation. Respir Res 22: 173, 2021 .

23. Myou S, Leff AR, Myo S, Boetticher E, Tong J, Meliton AY, Liu J, Munoz NM and Zhu X: Blockade of inflammation and airway hyperresponsiveness in immune-sensitized mice by dominant-negative phosphoinositide 3-kinase-TAT. J Exp Med 198: 1573-1582, 2003.

24. Ford JG, Rennick D, Donaldson DD, Venkayya R, McArthur C, Hansell E, Kurup VP, Warnock M and Grünig G: Il-13 and IFN-gamma: Interactions in lung inflammation. J Immunol 167: 1769-1777, 2001.

25. Livak KJ and Schmittgen TD: Analysis of relative gene expression data using real-time quantitative PCR and the 2(-Delta Delta C(T)) Method. Methods 25: 402-408, 2001 
26. Feng R, Adeniran SO, Huang F, Li Y, Ma M, Zheng P and Zhang G: The ameliorative effect of melatonin on LPS-induced Sertoli cells inflammatory and tight junctions damage via suppression of the TLR4/MyD88/NF- $\kappa \mathrm{B}$ signaling pathway in newborn calf. Theriogenology 179: 103-116, 2021.

27. O'Byrne PM and Inman MD: Airway hyperresponsiveness. Chest 123 (Suppl 3): 411S-6S, 2003.

28. Yamakage M, Iwasaki S and Namiki A: Guideline-oriented perioperative management of patients with bronchial asthma and chronic obstructive pulmonary disease. J Anesth 22: 412-428, 2008.

29. Vaschetto R, Bellotti E, Turucz E, Gregoretti C, Corte FD and Navalesi P: Inhalational anesthetics in acute severe asthma. Curr Drug Targets 10: 826-832, 2009.

30. Groeben H, Mitzner W and Brown RH: Effects of the alpha2-adrenoceptor agonist dexmedetomidine on bronchoconstriction in dogs. Anesthesiology 100: 359-363, 2004.

31. Türktan M, Güleç E, Hatipoğlu Z, Ilgınel MT and Özcengiz D: The effect of sevoflurane and dexmedetomidine on pulmonary mechanics in ICU patients. Turk J Anaesthesiol Reanim 47: 206-212, 2019

32. Ambesh SP and Dubey M: Effect of intramuscular dexmedetomidine administration before extubation on post-extubation haemodynamics, postoperative sedation, and analgesic requirements: A double blind placebo controlled study. Asian J Anesthesiol 59: 102-110, 2021.

33. Hwang L, Ko IG, Jin JJ, Kim SH, Kim CJ, Chang B, Rho JH, Moon EJ and Yi JW: Dexmedetomidine ameliorates memory impairment in sleep-deprived mice. Anim Cells Syst (Seoul) 23: 371-379, 2019

34. Geng Y, Li R, He SX, Yang HH, Deng QT, Shao XY, Wu YS, $\mathrm{Xu}$ WW and Ma Q: Dexmedetomidine attenuates acute lung injury induced by heatstroke and improve outcome. Shock 52 : 532-539, 2019.

35. Yang C, He L, Wang C, Huang Y, Wang A, Li X and Ao J: Dexmedetomidine alleviated lipopolysaccharide/D-galactosamine-induced acute liverinjury in mice. Int Immunopharmacol 72 : 367-373, 2019.

36. Zhi Y, Huang $H$ and Liang L: MFG-E8/integrin $\beta 3$ signaling contributes to airway inflammation response and airway remodeling in an ovalbumin-induced murine model of asthma. J Cel Biochem 119: 8887-8896, 2018.

37. Fahy JV: Type 2 inflammation in asthma-present in most, absent in many. Nat Rev Immunol 15: 57-65, 2015.

38. Ren M, Feng M, Long Z, Ma J, Peng X and He G: Allergic asthma-induced cognitive impairment is alleviated by dexamethasone. Front Pharmacol 12: 680815, 2021.

39. Lo D, Kennedy JL, Kurten RC, Panettieri RA Jr and Koziol-White CJ: Modulation of airway hyperresponsiveness by rhinovirus exposure. Respir Res 19: 208, 2018.

40. Yang M, Kumar RK and Foster PS: Interferon-gamma and pulmonary macrophages contribute to the mechanisms underlying prolonged airway hyperresponsiveness. Clin Exp Allergy 40: 163-173, 2010.

41. Duan J, Kang J, Qin W, Deng T, Liu H, Li B, Yu W, Gong S, Yang X and Chen M: Exposure to formaldehyde and diisononyl phthalate exacerbate neuroinflammation through NF- $\kappa \mathrm{B}$ activation in a mouse asthma model. Ecotoxicol Environ Saf 163: 356-364, 2018.
42. Kim E, Kim HC, Lee S, Ryu HG, Park YH, Kim JH, Lim YJ and Park HP: Dexmedetomidine confers neuroprotection against transient global cerebral ischemia/reperfusion injury in rats by inhibiting inflammation through inactivation of the TLR-4/NF-KB pathway. Neurosci Lett 649: 20-27, 2017.

43. Huang W, Li ML, Xia MY and Shao JY: Fisetin-treatment alleviates airway inflammation through inhbition of MyD88/NF- $\kappa$ B signaling pathway. Int J Mol Med 42: 208-218, 2018.

44. Tanic M, Yanowsky K, Rodriguez-Antona C, Andrés R, Márquez-Rodas I, Osorio A, Benitez J and Martinez-Delgado B: Deregulated miRNAs in hereditary breast cancer revealed a role for miR-30c in regulating KRAS oncogene. PLoS One 7: e38847, 2012.

45. Gao ZJ, Yuan WD, Yuan JQ, Yuan K and Wang Y: MiR-486-5p functions as an oncogene by targeting PTEN in non-small cell lung cancer. Pathol Res Pract 214: 700-705, 2018.

46. Fan HP, Wang SY, Shi YY and Sun J: MicroRNA-340-5p inhibits the malignant phenotypes of osteosarcoma by directly targeting NRF2 and deactivating the PI3K/AKT pathway. Eur Rev Med Pharmacol Sci 25: 3661-3669, 2021.

47. Bao Y, Zhu Y, He G, Ni H, Liu C, Ma L, Zhang L and Shi D: Dexmedetomidine attenuates neuroinflammation in LPS-Stimulated BV2 microglia cells through upregulation of miR-340. Drug Des Devel Ther 13: 3465-3475, 2019.

48. He L, Wang Z, Zhou R, Xiong W, Yang Y, Song N and Qian J: Dexmedetomidine exerts cardioprotective effect through miR-146a-3p targeting IRAK1 and TRAF6 via inhibition of the NF- $\kappa$ B pathway. Biomed Pharmacother 133: 110993, 2021.

49. Wei W, Sun Z, He S, Zhang W and Chen S: Protective role of dexmedetomidine against sevoflurane-induced postoperative cognitive dysfunction via the microRNA-129/TLR4 axis. J Clin Neurosci 92: 89-97, 2021.

50. Du XH, Li SS, Xiong GS, Yang GM, Shen W, Sun SB, Ye XL Li L and Weng ZY: Therapeutic efficacy of dexmedetomidine on chronic obstructive pulmonary disease via downregulating lncRNA PACER. Eur Rev Med Pharmacol Sci 24: 12963-12970, 2020.

51. Deng F, Cai L, Zhou B, Zhou Z and Xu G: Whole transcriptome sequencing reveals dexmedetomidine-improves postoperative cognitive dysfunction in rats via modulating IncRNA. 3 Biotech 10: 202, 2020.

52. Zhou Z, Chen Q, Wan L, Zheng D, Li Z and Wu Z: Dexmedetomidine protects hepatic cells against oxygen-glucose deprivation/reperfusion injury via lncRNA CCAT1. Cell Biol Int 42: 1250-1258, 2018

53. Takasaki Y, Kido T and Semba K: Dexmedetomidine facilitates induction of noninvasive positive pressure ventilation for acute respiratory failure in patients with severe asthma. J Anesth 23: 147-150, 2009.

54. Lee JA, Rowen DW and Rose DD: Bronchial thermoplasty: A novel treatment for severe asthma requiring monitored anesthesia care. AANA J 79: 480-483, 2011.

This work is licensed under a Creative Commons Attribution-NonCommercial-NoDerivatives 4.0 International (CC BY-NC-ND 4.0) License. 